\title{
Angiotensin II Increases Glucose Utilization during Acute Hyperinsulinemia via a Hemodynamic Mechanism
}

\author{
Thomas A. Buchanan, Hemant Thawani, Wagdy Kades, J. Gregory Modrall, Fred A. Weaver, Constance Laurel, \\ Roberta Poppiti, Anny Xiang, and Willa Hsueh \\ Departments of Medicine, Surgery, and Preventative Medicine, Los Angeles County-University of Southern California Medical Center \\ and the University of Southern California School of Medicine
}

\begin{abstract}
To determine whether hemodynamic changes can modulate insulin action in vivo, we administered angiotensin II $\left(\mathbf{A}_{\mathrm{II}}\right)$ to normal men under three separate, euglycemic conditions. First, in the presence of physiological hyperinsulinemia $(\sim 115 \mu \mathrm{U} / \mathrm{ml})$, infusion of $A_{\text {II }}$ at rates of 2,10 , and $20 \mathrm{ng} / \mathrm{min}$ per $\mathrm{kg}$ caused significant elevations of blood pressure, whole-body glucose clearance, and plasma insulin concentrations in an $\mathbf{A}_{\text {II }}$ dose-dependent manner. Second, in the presence of plasma insulin concentrations that stimulate glucose transport maximally $(\sim 5,000 \mu \mathrm{U} / \mathrm{ml}), A_{I I}$ infusions increased whole-body glucose clearance without enhancing glucose extraction across the leg. Third, in the presence of basal insulin concentrations $(\sim 13$ $\mu \mathrm{U} / \mathrm{ml}), A_{\text {II }}$ infusions had no effect on whole-body glucose turnover or leg glucose extraction. Thus, $A_{\text {II }}$ enhanced whole-body glucose utilization without directly stimulating glucose transport in a major skeletal muscle bed. To evaluate a possible hemodynamic mechanism for the effects of $A_{I I}$ on glucose utilization, we measured blood flow to two areas that differ in their sensitivity to insulin: the kidneys and the leg. We found that $A_{\text {II }}$ redistributed blood flow away from the predominantly insulinindependent tissues of the kidney and toward the insulin-sensitive tissues of the leg during both sham and hyperinsulinemic glucose clamps. The redistribution of flow had no effect on whole-body glucose turnover when leg glucose uptake was unstimulated (sham clamps). However, when leg glucose uptake was activated by insulin, the redistribution of flow caused a net increase in whole-body glucose utilization. Our findings indicate that hemodynamic factors can modulate insulin action in vivo. Furthermore, our results suggest that variable activity of the renin-angiotensin system may contribute to inconsistencies in the association between insulin resistance and hypertension. (J. Clin. Invest. 1993.92:720-726.) Key words: insulin sensitivity $\bullet$ hypertension $\bullet$ hemodynamics $\bullet$ blood flow $\bullet$ angiotensin II
\end{abstract}

\section{Introduction}

Resistance to insulin-mediated glucose disposal is a characteristic of some patients with essential hypertension (1-7). While a large body of evidence from other disease states indicates that insulin resistance may occur at the level of insulin-sensitive cells $(8-10)$, the mechanisms responsible for insulin resistance

Address reprint requests to Dr. Thomas A. Buchanan, Room 8250 General Hospital, 1200 N. State St., Los Angeles, CA 90033.

Received for publication 30 November 1992 and in revised form 9 March 1993.

J. Clin. Invest.

(C) The American Society for Clinical Investigation, Inc.

0021-9738/93/08/0720/07 \$2.00

Volume 92, August 1993, 720-726 in hypertensive individuals remain to be determined. Several recent studies indicate that insulin action in the intact organism may be regulated at steps proximal to insulin-mediated glucose uptake by cells. For example, Yang et al. (11) reported that transcapillary transport of insulin from plasma to interstitial fluid is rate limiting for insulin-mediated glucose uptake in dogs. Furthermore, Laasko et al. (12-14) and Anderson et al. (15) reported that stimulation of glucose uptake by insulin in humans is associated with, and perhaps partially determined by, an increase in blood flow to insulin-sensitive tissues. While the hemodynamic actions of insulin per se remain controversial (16), the data of Laasko et al. (12-14) and Anderson et al. (15) prompted us to postulate that vasopressors might modulate insulin action in humans through hemodynamic mechanisms. If proven, that hypothesis could be relevant to wholebody insulin sensitivity in different forms of hypertension. To test our hypothesis, we measured the effects of a vasopressor, angiotensin II $\left(\mathrm{A}_{\mathrm{II}}\right),{ }^{1}$ on whole-body glucose utilization, leg glucose extraction, and leg blood flow during hyperinsulinemic, euglycemic clamps in normal men. Our results indicate that $A_{I I}$ alters insulin action in vivo through a hemodynamic mechanism.

\section{Methods}

\section{Subjects}

Studies were performed on healthy Caucasian and black men ranging in age from 30 to $50 \mathrm{yr}$ and in body mass index (BMI) from 20 to 36 $\mathrm{kg} / \mathrm{m}^{2}$. All subjects gave written, informed consent for participation in the study, which was approved by the Research Committee of the Los Angeles County, University of Southern California (LAC+USC) Medical Center.

\section{Protocols}

The effect of $A_{\text {II }}$ on glucose metabolism was examined in three studies in which $A_{\text {II }}$ was administered during the last 90 min of 270-min euglycemic clamps or sham insulin infusions. In the first study $\left(A_{I I}\right.$ dose-response study), $A_{\text {II }}$ was infused at three different doses during euglycemic clamps performed at physiological hyperinsulinemia. In the second study (maximum insulin study), $A_{I I}$ was infused in the face of hyperinsulinemia that stimulates glucose utilization maximally in normal men $(12-14,17)$. In the third study (basal insulin study), $A_{\text {II }}$ was infused during a sham insulin infusion. For all protocols, subjects were admitted to the General Clinical Research Center of LAC+USC Medical Center, where they remained ambulatory and consumed a weightmaintaining diet for at least $3 \mathrm{~d}$ before metabolic testing.

$A_{I I}$ dose-response study. Seven men (four with a BMI $<27 \mathrm{~kg} / \mathrm{m}^{2}$ ) participated in this protocol. Overnight fasted subjects were placed in bed at 0600 hours and intravenous catheters were placed in a left ante-

1. Abbreviations used in this paper: $\mathrm{A}_{\mathrm{II}}$, angiotensin II; $\mathrm{A}-\mathrm{V}$, arterio-venous; BMI, body mass index; MAP, mean arterial pressure; PAH, $p$ aminohippurate. 
cubital vein for infusions and a right dorsal hand vein for blood sampling. The latter catheter was inserted in retrograde fashion and the hand was kept in a warming box at $70^{\circ} \mathrm{C}$ during blood sampling.

Beginning at 0700 hours, primed infusions of $3-\left[{ }^{3} \mathrm{H}\right] \mathrm{D}$-glucose $(30$ $\mu \mathrm{Ci}$ bolus and $0.3-\mu \mathrm{Ci} / \mathrm{min}$ infusion; Amersham Corp., Arlington Heights, IL) and $p$-aminohippurate (PAH; $4-\mathrm{mg} / \mathrm{kg}$ bolus and $10-\mathrm{mg} /$ min infusion; Merck, Sharp and Dohme, West Point, PA) were administered for $390 \mathrm{~min}$. Infusions of human insulin $(1 \mathrm{mU} / \mathrm{min}$ per $\mathrm{kg}$; Novolin R; Novo Nordisk, Princeton, NJ) and potassium phosphate $(10 \mathrm{meq}$ potassium $/ \mathrm{h}$ ) were started $120 \mathrm{~min}$ after the start of the tritiated glucose infusion and continued for $270 \mathrm{~min}$. Blood pressure (Dinamap; Critikon, Inc., Tampa, FL) and plasma glucose were measured at 5-min intervals, starting $30 \mathrm{~min}$ before the insulin infusion. Dextrose ( $20 \% \mathrm{wt} / \mathrm{vol}$ in water), labeled with $3-\left[{ }^{3} \mathrm{H}\right] \mathrm{D}$-glucose to a specific activity of $1.8 \mu \mathrm{Ci} / \mathrm{g}$, was given at rates sufficient to maintain basal glycemia during insulin infusions.

During the final $90 \mathrm{~min}$ of the insulin infusion, $A_{\text {II }}$ (Bachem California, Torrance, $C A$ ) was infused at one of three dose pairs ( 0.5 and $2,2.5$ and 10 , or 5 and $20 \mathrm{ng} / \mathrm{min}$ per $\mathrm{kg}$ ). The lower dose of each pair was given for $30 \mathrm{~min}$, followed by the higher dose for $60 \mathrm{~min}$. Each subject had three glucose clamps performed at least $1 \mathrm{wk}$ apart so that all subjects received all of the $A_{I I}$ dose pairs. The order of the three glucose clamps (i.e., the different $A_{I I}$ dose pairs) was varied among subjects.

Blood samples for plasma $\left[{ }^{3} \mathrm{H}\right]$ glucose measurements were obtained at $-30,-20,-10,30,60,90,120,150,160,170,180,200,210$, $220,230,240,250,260$, and $270 \mathrm{~min}$ relative to the start of the insulin infusion. Blood for plasma insulin and PAH measurements was obtained at $-30,-20,-10,160,170,180,250,260$, and 270 min relative to starting insulin. Samples were drawn into ice-cold heparinized tubes and plasma was separated and stored at $-20^{\circ} \mathrm{C}$ until analysis.

Maximum insulin study. Four lean subjects (BMI $<27 \mathrm{~kg} / \mathrm{m}^{2}$ ) participated in this protocol. The glucose clamp procedure was identical to that used for the dose-response study except: $(a)$ insulin was infused at $15 \mathrm{mU} / \mathrm{min}$ per $\mathrm{kg}$; $(b)$ potassium phosphate was infused at $15 \mathrm{meq} / \mathrm{h}$ during the insulin infusion; $(c)$ only the highest $\mathrm{A}_{\mathrm{II}}$ dose pair (5 and 20 $\mathrm{ng} / \mathrm{min}$ per $\mathrm{kg}$ ) was given; $(d)$ blood samples were obtained from indwelling right common femoral arterial and venous catheters which were placed at least $1 \mathrm{~h}$ before starting insulin and the location of which was verified by ultrasound; $(e)$ blood pressure and heart rate measurements were taken directly from the femoral arterial catheter using a pressure transducer (DTX Pressure Transducer System; Viggo-Spectramed, Oxnard, CA) and digital monitor (model 78353A; HewlettPackard Co., Palo Alto, CA); and (f) blood flow through the left common femoral artery was measured $\sim 3.5 \mathrm{~cm}$ above the profunda $f e$ moris artery by color flow duplex ultrasound scanning (Ultramark 9; Advanced Technologies Laboratories, Bothel, WA) during the basal, insulin-only, and insulin $+A_{\text {II }}$ infusion periods (defined below). During each period, five measurements of the maximum internal diameter of the artery (B-mode ultrasound) and the area under the linear blood velocity curve (pulsed Doppler ultrasound) during two cardiac cycles were taken by a registered vascular technologist who was unaware of the infusions that were being administered. The blood flow rate (crosssectional vessel area $\times$ time-averaged blood velocity) was calculated by software provided with the apparatus and a mean of the five flow measurements was taken as a single measure of flow for the infusion period. The coefficients of variation for the sets of five flow measurements averaged $12 \pm 1 \%$ overall and did not vary among infusion periods.

Arterial plasma was used for the glucose clamping procedure and for insulin, tracer, and PAH measurements in this maximum insulin study and the basal insulin study (below). Femoral venous glucose concentrations were measured at 5-min intervals during the basal, insulinonly, and insulin $+A_{I I}$ infusion periods to allow calculation of leg arterio-venous $(\mathrm{A}-\mathrm{V})$ glucose concentration differences.

Basal insulin study. The same four subjects who participated in the maximum insulin study underwent a second study, at least 1 wk later, to determine the effects of $A_{I I}$ on glucose utilization in the absence of infused insulin. The protocol was identical to that of the maximum insulin study, except: (a) $0.45 \%$ saline was infused instead of insulin; $(b)$ no potassium phosphate was administered; and (c) the volume of $20 \%$ dextrose infused during maximum insulin study was replaced by the same volume of $0.45 \%$ saline to control for possible effects of volume loading on hemodynamic parameters.

\section{Analytical methods}

Glucose was measured by glucose oxidase (Beckman Glucose Analyzer II; Beckman Instruments, Inc., Fullerton, CA). Insulin was measured with a charcoal precipitation radioimmunoassay (18) using guinea pig anti-porcine insulin antibodies and human insulin standards (both from Novo Pharmaceuticals, Danbury, CT). All samples from one subject were run in the same insulin assay. Tritiated glucose concentrations were measured by precipitation of plasma proteins with barium sulfate and zinc chloride, followed by drying of the supernatant, resuspension in water, and counting in a liquid scintillation counter. Counts were corrected for incomplete recovery in each assay, as assessed by the recovery of a known amount of radioactive glucose from pooled human plasma. PAH concentrations were measured chemically (19); all samples from one glucose clamp were run in the same PAH assay.

\section{Data analysis}

Basal rates of whole-body glucose appearance $(R a)$ were calculated by the steady-state equation of Steele (20). Rates of whole-body glucose utilization ( $R d$; milligrams per minute per kilogram body weight) and endogenous glucose appearance during insulin infusions were calculated by the method of Finegood et al. (21). Glucose clearance, calculated as $R d / G$, where $G$ is the plasma glucose concentration in milligrams per milliliter, was used as a measure of glucose utilization that is less dependent on glycemia than is $R d(22)$. PAH clearance from plasma, measured as an index of renal plasma flow, was calculated as $I / C$, where $I$ is the infusion rate (milligrams per minute) and $C$ is the plasma concentration (milligrams per milliliter) of PAH.

Data are presented as means \pm SEM. For analysis of plasma glucose and insulin concentrations, glucose clearance and endogenous production rates, mean arterial pressure (MAP; [systolic pressure + diastolic pressure $\times 2] / 3$ ), heart rate, plasma PAH clearance, femoral arterial blood flow, and femoral A-V glucose concentration differences, an individual mean value for each parameter was calculated during three periods of each glucose clamp: basal ( $30 \mathrm{~min}$ before starting insulin or sham infusion), insulin-only (150-180 min after starting insulin or sham), and insulin $+A_{\text {II }}$ (240-270 min after starting insulin or sham). The individual means were then compared by repeated measures analysis of variance for differences among the three glucose clamps (i.e., clamps performed with different $\mathrm{A}_{\text {II }}$ dose pairs) in the dose-response study and for differences among infusion periods in all three studies. Tukey's test was applied post hoc to determine which data differed when analysis of variance revealed a significant difference among clamp protocols or infusion periods. Analysis of linear trends was used to test for $A_{I I}$ dose-dependent differences in MAP and glucose clearance in the insulin $+A_{I I}$ period of the dose-response study. In that study, the effects of $A_{\text {II }}$ on glucose metabolism were similar in lean and obese subjects; data from those two groups were combined for analysis.

\section{Results}

Effect of $A_{I I}$ during physiological hyperinsulinemia $\left(A_{I I}\right.$ doseresponse study). Plasma glucose and insulin concentrations(Table I) did not differ significantly among the three clamp protocols during basal, insulin-only, or insulin $+A_{\text {II }}$ infusion periods. Likewise, plasma glucose concentrations did not differ significantly over time in any of the three clamp protocols. Plasma insulin concentrations increased significantly over time in all three protocols. In addition to the expected increase above basal due to the infusion of insulin alone, plasma insulin concentrations increased further during the infusion of $\mathrm{A}_{\mathrm{II}}$ at all dose pairs. The increase in plasma insulin observed during $A_{I I}$ infu- 
Table I. Plasma Glucose and Insulin Concentrations and Renal Plasma Flow before and during Euglycemic Clamps at Physiological Hyperinsulinemia

\begin{tabular}{|c|c|c|c|}
\hline $\mathrm{A}_{\|}$Infusion (ng/min per kg) & Basal & $\begin{array}{c}\text { Insulin } \\
\text { only }\end{array}$ & Insulin $+\mathbf{A}_{\|}$ \\
\hline \multicolumn{4}{|l|}{ Plasma glucose (mg/dl) } \\
\hline 0.5 and 2 & $94 \pm 2$ & $95 \pm 2$ & $95 \pm 3$ \\
\hline 2.5 and 10 & $94 \pm 1$ & $95 \pm 1$ & $95 \pm 2$ \\
\hline 5 and 20 & $94 \pm 1$ & $96 \pm 1$ & $93 \pm 1$ \\
\hline \multicolumn{4}{|l|}{ Plasma insulin $(\mu \mathrm{U} / \mathrm{ml})$} \\
\hline 0.5 and 2 & $10 \pm 3$ & $118 \pm 9^{*}$ & $135 \pm 18^{*}$ \\
\hline 2.5 and 10 & $9 \pm 3$ & $117 \pm 13^{*}$ & $144 \pm 17^{* \ddagger}$ \\
\hline 5 and 20 & $10 \pm 3$ & $107 \pm 14^{*}$ & $142 \pm 17^{* \pm}$ \\
\hline \multicolumn{4}{|l|}{ Renal plasma flow (ml/min) } \\
\hline 0.5 and 2 & $705 \pm 40$ & $761 \pm 45^{*}$ & $595 \pm 25^{* \pm}$ \\
\hline 2.5 and 10 & $732 \pm 42$ & $779 \pm 43^{*}$ & $501 \pm 25^{* \neq}$ \\
\hline 5 and 20 & $695 \pm 50$ & $725 \pm 58^{*}$ & $444 \pm 34^{* \pm}$ \\
\hline
\end{tabular}

Each of seven normal men had three 270-min euglycemic clamps. $A_{\|}$ was infused at one of the three dose pairs listed during the last 90 min of each clamp, the lower $A_{\|}$dose of each pair for $30 \mathrm{~min}$, followed by the higher dose for $60 \mathrm{~min}$. Renal plasma flow was determined by clearance of PAH during equilibrium infusions. Numbers denote mean \pm SEM data from the 30 -min period before insulin infusions (basal), the final $30 \mathrm{~min}$ of the insulin-only period, and the final 30 min of the insulin $+A_{\|}$period. Glucose and insulin concentrations did not differ significantly among $A_{\|}$doses for any infusion period. ${ }^{*} P<0.05$ vs basal period, same $A_{\|}$dose; ${ }^{\ddagger} P<0.05$ vs insulin-only period, same $A_{\|}$dose.

sions tended to parallel the $A_{I I}$ infusion rates (14, 22, and 33\% increase during lowest, middle, and highest $A_{\text {II }}$ dose pairs, respectively), but the increase above the insulin-only period was statistically significant only for clamps performed with the two higher $\mathrm{A}_{\text {II }}$ dose pairs.

MAP did not differ significantly among the three clamp protocols during the basal or insulin-only periods (Fig. 1, top). Likewise, no difference in mean, systolic, or diastolic blood pressures was observed between the basal and insulin-only periods of any protocol. $A_{\text {II }}$ increased MAP in all three protocols in parallel with the final $\mathrm{A}_{\mathrm{II}}$ doses $(P<0.001$ by analysis of linear trends), reflecting the dose-dependent impact of $A_{\text {II }}$ on blood pressure.

Glucose clearance was similar among the three glucose clamp protocols during the basal period (Fig. 1, middle) and clearance increased $\sim 2.5$-fold during the insulin-only infusion period of each protocol. Thus, there were no interprotocol differences in glucose clearance during the infusion of insulin alone. $A_{\text {II }}$ increased glucose clearance by 23,41 , and $72 \%$ above the insulin-only period for the lowest, middle, and highest $A_{I I}$ dose pairs, respectively. The final rates of glucose clearance in the three protocols paralleled the final $A_{\text {II }}$ doses $(P<0.01$ by analysis of linear trends), suggesting a causal relationship between $A_{I I}$ administration and increased glucose clearance. Insulin suppressed endogenous glucose production in all three protocols (Fig. 1, bottom) and $\mathrm{A}_{\mathrm{II}}$ did not alter glucose production further in any protocol.

Renal plasma flow (Table I) increased significantly above basal during the insulin-only periods of all three clamp protocols. However, the magnitude of the increases was small, repre-

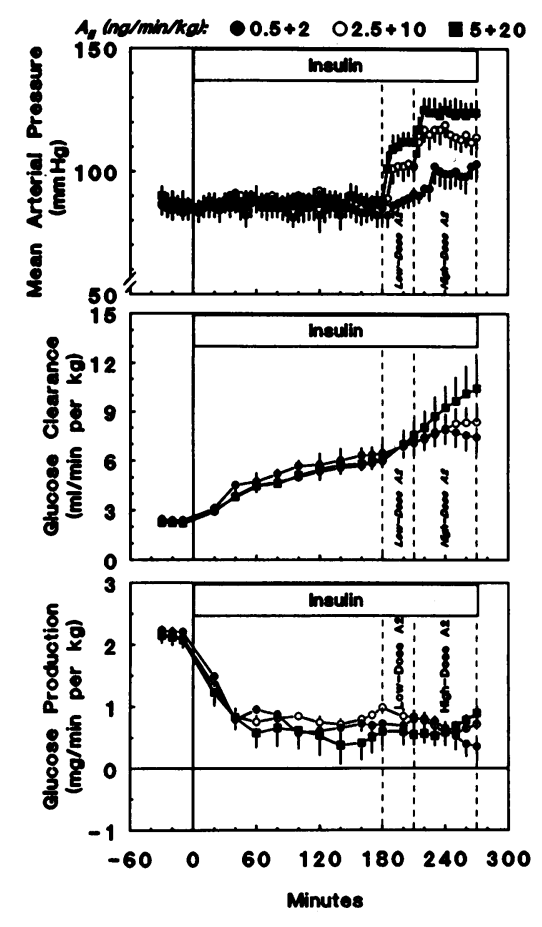

Figure 1. MAP (cuff measurement) and whole-body rates of glucose clearance and production during euglycemic clamps performed at physiological hyperinsulinemia. Clamps were performed as described in Table I. None of the three parameters differed among protocols during the basal (-30-0 $\mathrm{min}$ ) or insulinonly (150-180 min) periods. Analysis of linear trends revealed $A_{\text {II }}$ dose-dependent increases in MAP ( $P$ $<0.001)$ and wholebody glucose clearance $(P<0.01)$ during the insulin $+A_{I I}$ period (240-270 min) as compared with the insulinonly period. $A_{\mathrm{II}}$ administration did not alter hepatic glucose production.

senting only $6.3 \pm 1.2 \%$ of basal renal plasma flow overall. Renal plasma flow decreased significantly during each $\mathrm{A}_{\text {II }}$ infusion (Table I). Moreover, the change in renal flow between the insulin-only and insulin $+A_{\text {II }}$ periods was greater for each of the two higher $A_{\text {II }}$ dose pairs than for the lowest dose pair $(-278 \pm 23$ and $-281 \pm 27$ vs $-166 \pm 23 \mathrm{ml} / \mathrm{min}$, respectively; $P$ $<0.001)$.

Taken together, the findings of the $\mathrm{A}_{\text {II }}$ dose-response study indicated that under conditions of physiological hyperinsulinemia and euglycemia, $A_{\text {II }}$ simultaneously increased blood pressure, plasma glucose clearance, and plasma insulin. By contrast, $A_{\text {II }}$ decreased renal plasma flow and had no detectable impact on the ability of insulin to suppress endogenous glucose production.

Effects of $A_{I I}$ during maximum hyperinsulinemia (maximum insulin study). To determine whether the impact of $\mathrm{A}_{\mathrm{II}}$ on glucose clearance was mediated solely through increased plasma insulin concentrations, we performed additional $A_{\text {II }}$ infusions in four subjects after raising plasma insulin to a level at which greater hyperinsulinemia would not be expected to increase whole-body glucose utilization $(12-14,17)$. During those studies, plasma glucose concentrations (Table II) did not differ significantly among basal, insulin-only, and insulin $+\mathrm{A}_{\mathrm{II}}$ infusion periods. The insulin infusions raised plasma insulin concentrations above $4,000 \mu \mathrm{U} / \mathrm{ml}$ in all four subjects (Table II). Addition of $A_{\text {II }}$ at a final rate of $20 \mathrm{ng} / \mathrm{min}$ per $\mathrm{kg}$ was associated with a $14 \pm 3 \%$ increase in plasma insulin concentrations, which increased in all four subjects $(P<0.02$ vs insulinonly period).

MAP measured directly from the femoral artery (Fig. 2, top) was the same during the basal and insulin-only infusion periods $\left(96 \pm 6\right.$ vs $96 \pm 5 \mathrm{mmHg}$ ). $A_{\text {II }}$ increased MAP to $115 \pm 6$ $\mathrm{mmHg}$. Heart rates increased during insulin infusions in all 
Table II. Arterial Plasma Glucose and Insulin Concentrations and Femoral A-V Glucose Concentration Differences before and during Euglycemic Clamps at Maximum Hyperinsulinemia and before and during Sham Insulin Infusions

\begin{tabular}{|c|c|c|c|}
\hline Maximum insulin clamp & Basal & $\begin{array}{c}\text { Insulin } \\
\text { only }\end{array}$ & Insulin $+\mathbf{A}_{\|}$ \\
\hline Arterial glucose (mg/dl) & $94 \pm 4$ & $97 \pm 1$ & $96 \pm 2$ \\
\hline Arterial insulin $(\mu \mathrm{U} / \mathrm{ml})$ & $14 \pm 5$ & $4,999 \pm 396^{\ddagger}$ & $5,712 \pm 410^{\ddagger 5}$ \\
\hline A-V glucose difference $(\mathrm{mg} / \mathrm{dl})$ & $4 \pm 2$ & $32 \pm 3^{\ddagger}$ & $25 \pm 5^{\ddagger}$ \\
\hline Sham insulin infusion & Basal & $\begin{array}{l}\text { Sham } \\
\text { insulin }\end{array}$ & $\begin{array}{c}\text { Sham } \\
\text { insulin }+A_{\|}\end{array}$ \\
\hline Arterial glucose (mg/dl) & $96 \pm 2$ & $93 \pm 2$ & $90 \pm 2^{*}$ \\
\hline Arterial insulin $(\mu \mathrm{U} / \mathrm{ml})$ & $13 \pm 2$ & $9 \pm 1$ & $6 \pm 1^{*}$ \\
\hline A-V glucose difference $(\mathrm{mg} / \mathrm{dl})$ & $4 \pm 1$ & $4 \pm 1$ & $4 \pm 1$ \\
\hline
\end{tabular}

Four normal men had a euglycemic insulin infusion $(15 \mathrm{mU} / \mathrm{min}$ per kg; Maximum insulin clamp) and an infusion of saline (Sham insulin infusion) on separate occasions. Blood was sampled from a common femoral artery and vein during the basal, insulin or sham, and insulin $+A_{\|}$or sham $+A_{\|}$infusion periods, as described in Table I. ${ }^{*} P$ $<0.05 ;{ }^{\ddagger} P<0.01$ vs basal period, same $A_{\|}$dose; ${ }^{\S} P<0.02$ vs insulin-only period, same $A_{\|}$dose.

subjects, from $60 \pm 2$ beats/min during the basal period to $68 \pm 1$ beats/min $(P<0.04)$. A $\mathrm{III}_{\mathrm{II}}$ had no additional effect on heart rates ( $70 \pm 4$ beats $/ \mathrm{min} ; P>0.4$ compared with the insulin-only period).

Whole-body glucose clearance (Fig. 2, bottom) increased from $2.7 \pm 0.1 \mathrm{ml} / \mathrm{min}$ per $\mathrm{kg}$ during the basal period to $11.0 \pm 0.6 \mathrm{ml} / \mathrm{min}$ per $\mathrm{kg}$ by the end of the insulin-only infusion period. $A_{\mathrm{II}}$ increased glucose clearance further, to $14.6 \pm 1.4 \mathrm{ml} /$ min per $\mathrm{kg}\left(P<0.001\right.$ vs insulin-only). $A_{\mathrm{II}}$ increased glucose

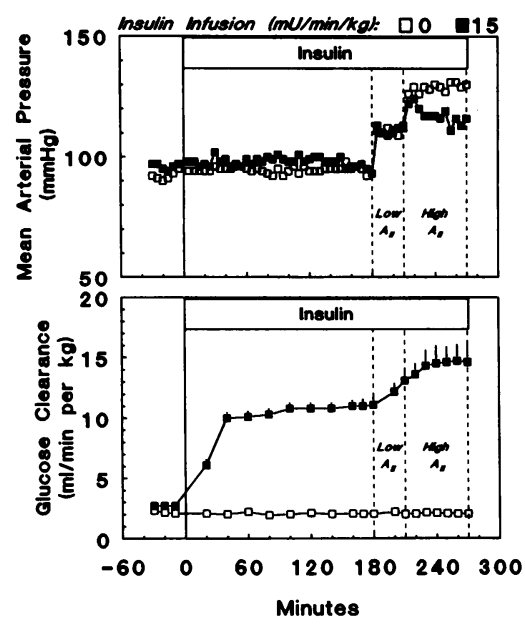

Figure 2. MAP (direct femoral measurement) and whole-body glucose clearance during glucose clamps performed at maximum hyperinsulinemia $(15 \mathrm{mU} / \mathrm{min}$ per kg; closed symbols) and during sham insulin infusions (open symbols). Low $A_{I I}$ and High $A_{I I}$ denote $\mathrm{A}_{\text {II }}$ infusion rates of 5 and $20 \mathrm{ng} / \mathrm{min}$ per $\mathrm{kg}$, respectively. Analysis of variance revealed no change in MAP during insulin or sham infusions (150$180 \mathrm{~min}$ ) compared

with the basal period ( $-30-0 \mathrm{~min})$. The increase in MAP during the higher $\mathrm{A}_{\mathrm{II}}$ infusion was less during maximum insulin than during sham insulin $(P=0.03)$. Glucose clearance increased $(P<0.001)$ when $A_{\text {II }}$ was added to maximum insulin infusions. $A_{\text {II }}$ had no effect on glucose turnover in the sham study.

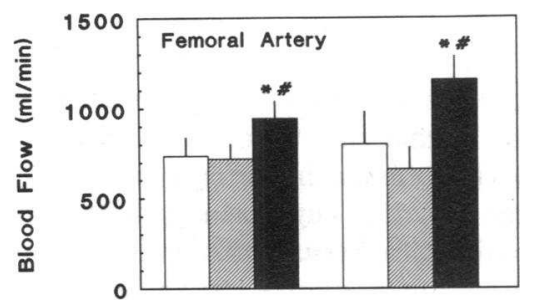

Figure 3. Femoral arterial blood flow and renal plasma flow during sham insulin infusions (left set of bars) and maximum insulin infu-

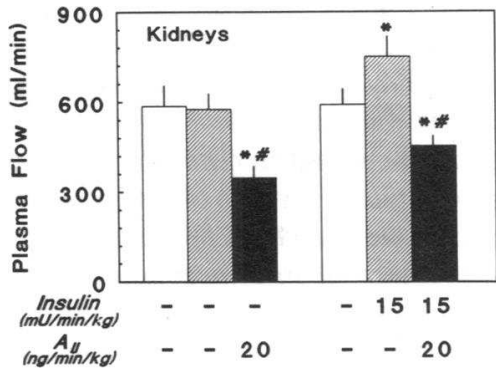
sions (right set of bars). Flows were measured during the steady-state basal (open bars), insulin or sham (hatched bars) and insulin $+\mathrm{A}_{\mathrm{II}}$ or sham $+\mathrm{A}_{\text {II }}$ (solid bars) infusion periods. ${ }^{*} P<0.01$ vs basal period; " $P<0.02$ vs insulin or sham only period.

clearance in all four subjects by $19-50 \%$ (mean, $32 \pm 7 \%$ ). By contrast, $A_{\text {II }}$ did not increase femoral $\mathrm{A}-\mathrm{V}$ glucose concentration differences significantly (Table II). In fact, the A-V glucose difference declined by $7-15 \mathrm{mg} / \mathrm{dl}$ during $A_{\mathrm{II}}$ infusions in three of the four subjects, while the A-V difference increased by 4 $\mathrm{mg} / \mathrm{dl}$ in the fourth subject.

Endogenous glucose production was suppressed to rates which were not significantly different from zero $(0.45 \pm 0.23$ $\mathrm{mg} / \mathrm{min}$ per $\mathrm{kg}$ ) during insulin infusions alone and $\mathrm{A}_{\mathrm{II}}$ did not alter glucose production rates further $(-0.59 \pm 0.30 \mathrm{mg} / \mathrm{min}$ per $\mathbf{k g}$ ).

Femoral arterial blood flow (Fig. 3, top) did not differ significantly between the basal and insulin-only infusion periods. Administration of $A_{I I}$ increased femoral flow in all four subjects by $81 \pm 14 \%$ (range $49-117 \%$ ) above the insulin-only period ( $P$ $<0.001$ ). Renal plasma flow (Fig. 3, bottom) increased above basal in all subjects during the infusion of insulin alone $(P$ $<0.01$ vs basal period) and renal flow decreased to levels below basal in all subjects during the $A_{I I}$ infusions $(P<0.01$ vs insulin-only and basal periods).

Effect of $A_{I I}$ in the absence of infused insulin (basal insulin $s t u d y)$. Plasma glucose and insulin concentrations fell slightly but significantly in fasting subjects during the 390-min study $(P$ $\leq 0.002$ for each; Table II). However, glucose turnover did not change significantly during the study, despite the fact that $\mathrm{A}_{\mathrm{II}}$ administration during the final 90 min increased the MAP by $38 \pm 3 \mathrm{mmHg}$. That increase was significantly greater than the $20 \pm 3 \mathrm{mmHg}$ rise in MAP observed when $A_{\text {II }}$ was infused at the same rate during maximum hyperinsulinemia $(P=0.03)$. $\mathrm{A}_{\text {II }}$ infusions had no effect on femoral $\mathrm{A}-\mathrm{V}$ glucose concentration differences in the face of basal insulin levels (Table II). Femoral arterial blood flow did not change during the saline infusions (Fig. 3) but increased during $A_{\text {II }}$ infusions in all four subjects by $34 \pm 10 \%$ (range 18-62\%). This increase in flow was less than the increase observed when $A_{\text {II }}$ was infused during maximum hyperinsulinemia $(81 \pm 14 \%)$, although the difference between studies was of borderline statistical significance $(P=0.06)$. Renal plasma flow was unchanged during saline infusions but declined significantly during $A_{I I}$ infusions (Fig. 3 ). The change in renal flow was less than the change observed when $A_{I I}$ was given during maximum insulin infusions $(-228 \pm 37$ vs $-296 \pm 44 \mathrm{ml} / \mathrm{min}$, respectively; $P<0.01$ ). 


\section{Discussion}

These studies were designed to test whether $A_{\text {II }}$ can modify insulin action in humans. To that end, we measured wholebody glucose turnover rates in normal men during the administration of $A_{I I}$ under three separate, euglycemic conditions. First, in the presence of physiological hyperinsulinemia, administration of $A_{I I}$ in doses from 2 to $20 \mathrm{ng} / \mathrm{min}$ per $\mathrm{kg}$ increased glucose clearance in a dose-dependent fashion. Plasma insulin concentrations also increased during $A_{\text {II }}$ administration, reflecting a reduction in whole-body insulin clearance that may have been mediated by reduced renal blood flow in response to $\mathrm{A}_{\mathrm{II}}$. To determine whether the increased glucose clearance observed during $A_{I I}$ infusions was purely a result of the increased plasma insulin concentrations, we tested the effects of $A_{I I}$ on glucose utilization in the presence of insulin concentrations that have been shown to stimulate glucose uptake maximally in vivo $(12-14,17)$. In that setting, an increase in plasma insulin would not be expected to increase whole-body glucose clearance. However, $\mathrm{A}_{\text {II }}$ increased glucose clearance by $32 \%$ during maximum hyperinsulinemia, indicating that the augmentation of glucose utilization by $A_{I I}$ was not mediated through an increase in plasma insulin. Furthermore, $A_{I I}$ did not increase femoral $\mathrm{A}-\mathrm{V}$ glucose concentration differences during maximum hyperinsulinemia, suggesting that $A_{\text {II }}$ did not directly stimulate glucose transport into leg tissues, including skeletal muscle. The lack of a direct effect of $A_{\text {II }}$ on cellular glucose uptake was further supported by our observation that $A_{I I}$ had no detectable effect on whole-body glucose turnover or leg glucose extraction in the face of basal insulin levels. Thus, the effect of $A_{\text {II }}$ to augment glucose utilization could not be explained solely by an increase in circulating insulin levels or by a direct effect of $A_{I I}$ to stimulate glucose transport into tissues of the leg.

Since $A_{I I}$ did not appear to stimulate glucose transport directly, we examined an alternative possibility that changes in regional blood flow might account for the effect of $A_{I I}$ to enhance insulin action in vivo. We found that renal plasma flow was reduced, while femoral arterial flow was increased during $A_{\text {II }}$ infusions. The qualitatively reciprocal changes in flow to the kidneys and legs are consistent with published reports that $A_{\text {II }}$ reduces splanchnic and renal blood flow (23-27) while increasing leg blood flow $(23,24)$. Those actions appear to reflect the fact that $A_{I I}$ increases resistance more in renal and splanchnic vessels than in femoral vessels $(28,29)$, since direct actions of $A_{\text {II }}$ on the femoral vasculature serve to reduce leg blood flow (30). The differential sensitivity of vascular beds to $A_{I I}$ results in a redistribution of cardiac output, which may be constant or reduced during $A_{\text {II }}$ administration (28), away from tissues that respond minimally to insulin and toward tissues (e.g., skeletal muscle) in which insulin stimulates glucose uptake. Such a redistribution of flow can explain the two patterns of glucose metabolism that we observed in response to $A_{I I}$. During hyperinsulinemia, when muscle glucose transport is activated compared with insulin-independent tissues, increased leg blood flow should increase the mass of glucose taken up by the legs unless the increased flow is counterbalanced by a reduction in glucose extraction. Reduced extraction could result from shunting of blood past glucose-utilizing tissues or from a direct inhibition of cellular glucose transport (14). In fact, we did observe a slight reduction in glucose extraction during insu- lin $+A_{\text {II }}$ infusions. However, the magnitude of that reduction ( $\leq 40 \%$ below insulin infusions alone) was consistently less than the increase in femoral blood flow effected by $A_{\text {II }}$ during hyperinsulinemia (49-117\%). Thus, there must have been a net increase in leg glucose utilization during insulin $+A_{I I}$ infusions. This finding suggests that $A_{\text {II }}$ recruited capillary beds supplying insulin-sensitive tissues, since we did not observe any direct action of $\mathrm{A}_{\mathrm{II}}$ on leg glucose extraction in sham glucose clamps. During basal insulinemia, when muscle glucose transport is not activated compared with insulin-independent tissues, redistribution of blood flow toward the leg should not increase whole-body glucose utilization. That prediction is consistent with our finding that $A_{I I}$ infusions had no effect on glucose turnover rates during sham glucose clamps. Thus, taken together, our data on regional blood flow patterns and leg glucose extraction indicate that a hemodynamic mechanism, rather than a direct effect of $A_{I I}$ on glucose transport, was responsible for the acute action of $A_{I I}$ to augment insulin-mediated utilization in normal men.

Just as $A_{I I}$ augmented the metabolic effects of insulin, insulin appeared to alter the hemodynamic actions of $A_{I I}$. The most direct evidence for such an alteration comes from a comparison of the blood pressure responses to $A_{I I}$, which were blunted in all subjects during maximum hyperinsulinemia as compared with the studies performed during basal insulinemia. This finding differs from the study of Gans et al. (31), who reported that acute, physiological hyperinsulinemia neither blunted nor enhanced the blood pressure responses of normal men to graded $A_{I I}$ infusions. The different results between the two studies may be related to the insulin doses used, since we also observed that physiological hyperinsulinemia $(\sim 100 \mu \mathrm{U} /$ $\mathrm{ml}$ ) during glucose clamps did not blunt the pressor responses to $A_{I I}$ in normal or hypertensive men (T. Buchanan, $H$. Thawani, and W. Hsueh, unpublished observations). A second piece of evidence indicating that insulin modified the hemodynamic actions of $A_{I I}$ was the greater increase in femoral arterial blood flow that occurred when $A_{I I}$ was given during maximum hyperinsulinemia as compared with basal insulinemia $(81 \pm 14$ vs $32 \pm 7 \%$, respectively). The greater increase in flow was observed in all four subjects despite careful matching of the volumes infused during the two protocols. At the same time, renal plasma flow was decreased more by $A_{\text {II }}$ infusions during maximum hyperinsulinemia than during the basal insulin studies. Whether this apparent enhancement of $\mathrm{A}_{\mathrm{II}}$-mediated redistribution of flow was related to specific effects of insulin on vascular reactivity or to changes in cardiac output during hyperinsulinemia (32) remains to be determined.

We made several additional observations relevant to published data on hemodynamic effects of insulin. First, we noted no increase of blood pressure during infusions of insulin to create physiological or pharmacological hyperinsulinemia. This finding is in agreement with some $(33,34)$ but not all $(15$, 35 ) reports about the effects of acute, euglycemic hyperinsulinemia on blood pressure in normal humans. Second, heart rates increased in all four subjects during maximum insulin infusions, but did not change significantly when the same subjects underwent sham glucose clamps. The finding of an increased heart rate during acute hyperinsulinemia is in agreement with the data of Rowe et al. (34) and Anderson et al. (15, 35). The increased heart rate could reflect activation of the sympathetic nervous system by insulin $(15,32-36)$ or reflex compensation 
for insulin-mediated vasodilation $(12-15,32)$. Our studies do not allow us to distinguish definitively between those mechanisms. However, in contrast to the reports of Laasko et al. (12-14) and Anderson et al. (15), but in agreement with the report of Natali et al. (16), we did not see increased peripheral blood flow that might reflect peripheral vasodilation during maximum insulin infusions. We do not know whether the inconsistency among studies is due to methodological differences in blood flow measurements or to other, unidentified factors. Additional studies will be required to fully define the effects of insulin on peripheral blood flow. Finally, we noted a consistent increase in renal plasma flow during insulin infusions. The increase was only $6 \%$ above basal during physiological hyperinsulinemia, an increase that could have resulted from the fluid infused as part of the glucose clamp procedure. Indeed, DeFronzo et al. (37) and Norgaard et al. (38) did not find increased renal plasma flow in dogs or humans, respectively, when euglycemic clamps were performed with physiological insulin concentrations. By contrast, we observed a $27 \%$ increase in renal plasma flow during maximum insulin clamps. Since no significant increase in renal flow occurred during sham clamps, we conclude that pharmacological hyperinsulinemia increased renal plasma flow in our normal subjects. Whether the increase resulted from a direct action of insulin on the renal vasculature or from secondary alterations of other hormones or nonglucose nutrients remains to be determined.

The duplex scanning technique that we used to measure femoral arterial flow has been shown by Zierler et al. (39) to measure femoral blood flow accurately when compared with direct measurements in baboons during exsanguination. The exsanguination model differs slightly from normal arterial flow in that flow during exsanguination is monophasic, consisting only of forward flow, while normal flow is triphasic, consisting of systolic and late diastolic forward flow plus a small component of early diastolic reverse flow. The pulsed Doppler method used in this study did not include the reverse flow component in the calculation of blood velocity. As a result, forward flow may have been overestimated to some extent. Indeed, basal femoral arterial blood flow rates in our normal subjects $(\sim 730 \mathrm{ml} / \mathrm{min})$ were greater than resting femoral arterial $(\sim 420 \mathrm{ml} / \mathrm{min})$ and venous $(\sim 270 \mathrm{ml} / \mathrm{min})$ blood flow rates reported in subjects similar to ours by Gasic et al. (30) and Laasko et al. (12), respectively. The wide variation in flow rates among studies reflects the difficulty of measuring peripheral blood flow in humans, along with the fact that there is no universally accepted method with which to make such measurements. However, three pieces of evidence suggest that any overestimation of flow in our study did not lead to erroneous conclusions about the effects of $A_{I I}$ on femoral blood flow. First, review of the photographs of blood velocity profiles from our subjects revealed a pattern of increased forward flow in late diastole during the $A_{I I}$ infusions. This finding is consistent with redistribution of flow from high resistance vascular beds (e.g., renal and splanchnic beds) to lower resistance beds in the legs during diastole. Second, our blinded study design and the stability of femoral blood flow measurements during the basal and sham infusion periods (Fig. 3) suggest that our flow measurements detected true changes in femoral arterial flow related to the infusion of $A_{\text {II }}$. Finally, the data of Zierler et al. (39) indicate that ultrasonographically determined flow rates increase in direct proportion to actual flow rates, allowing us to draw conclusions about relative changes in femoral flow during $A_{\text {II }}$ infusions. Those relative changes, combined with the data on renal plasma flow and femoral A-V glucose concentration differences, indicate that $A_{I I}$ increased whole-body glucose utilization in large part through hemodynamic mechanisms.

Although no direct extrapolation can be made from our findings during acute insulin and $\mathrm{A}_{\mathrm{II}}$ infusions to chronic effects of $A_{I I}$ on glucose metabolism, our results suggest that hypertensive conditions characterized by activation of the reninangiotensin system will not be associated with resistance to insulin-mediated glucose disposal. Most published data from patients with essential hypertension neither support nor refute that suggestion, since the renin-angiotensin system generally has not been characterized in studies of insulin action in human hypertension. However, our own data (40) and those of Kotchen et al. (41) from rats, and existing data from humans (42), indicate that one form of high-renin hypertension, renovascular hypertension, is associated with normal or enhanced insulin action on glucose metabolism. Those data, together with the findings of this study, suggest that the status of the renin-angiotensin system is one factor that could contribute to the inconsistent association between hypertension and insulin resistance in humans and experimental animals (40-43).

In summary, we have shown that acute administration of $A_{\text {II }}$ to normal men during euglycemic hyperinsulinemia increases whole-body glucose utilization. The effect appears to result from hemodynamic actions of $A_{\text {II }}$ rather than from a direct effect of $A_{I I}$ to stimulate glucose transport by cells. Our findings indicate that vasopressor agents can modify insulin action through hemodynamic mechanisms. Furthermore, the data suggest that characterization of the renin-angiotensin system may be important in studies of the relationship between hypertension and insulin resistance.

\section{Acknowledgments}

We are grateful to Lilit Yegyiant and George Sipos for their excellent technical assistance, to the nurses of the General Clinical Research Center at LAC+USC Medical Center for their assistance in the performance of the inpatient studies, and to Dr. Richard Bergman for his helpful comments during preparation of the manuscript.

This work was supported by Specialized Center of Research grant 1P50-HL4404 from the National Heart, Lung and Blood Institute and grant M01 RR-43 from the National Center for Research Resources of the General Clinical Research Centers.

\section{References}

1. Berglund, G., B. Larsson, O. Anderson, O. Larsson, K. Svardsudd, P. Bjorntorp, and L. Wilhelmsen. 1976. Body composition and glucose metabolism in hypertensive middle aged men. Acta Med. Scand. 200:163-169.

2. Singer, P., W. Godicke, S. Voigt, I. Hajdu, and M. Weiss. 1985. Postprandial hyperinsulinemia in patients with mild essential hypertension. Hypertension (Dallas). 7:182-186.

3. Modan, M., H. Halkin, S. Almog, A. Lusky, A. Eshkol, M. Shef, A. Shitrit, and Z. Fuchs. 1985. Hyperinsulinemia. A link between hypertension obesity and glucose intolerance. J. Clin. Invest. 75:809-817.

4. Manicardi, V., L. Camellini, G. Bellodi, C. Coscelli, and E. Ferrannini. 1986. Evidence of an association of high blood pressure and hyperinsulinemia in obese men. J. Clin. Endocrinol. Metab. 62:1302-1304.

5. Ferrannini, E., R. Buzzigoli, R. Bonadonna, M. A. Giorico, M. Oleggini, L. Graziadei, R. Pedrinelli, L. Brandi, and S. Bevilacqua. 1987. Insulin resistance in essential hypertension. N. Engl. J. Med. 317:350-357.

6. Shen, D.-C., S.-M. Sheih, M.-T. Fuh, D.-A. Wu, Y.-D. I. Chen, and G. M. 
Reaven. 1988. Resistance to insulin-stimulated glucose uptake in patients with hypertension. J. Clin. Endocrinol. Metab. 66:580-583.

7. Pollare, T., H. Lithell, and C. Berne. 1990. Insulin resistance is a characteristic feature of primary hypertension independent of obesity. Metab. Clin. Exp. 39:167-174

8. Dohm, G. L., E. B. Tapscott, W. J. Pories, D. J. Dabbs, E. G. Flickinger, D. Meelheim, T. Fushiki, S. M. Atkinson, C. W. Elton, and J. F. Caro. 1988. An in vitro human muscle preparation suitable for metabolic studies. Decreased insulin stimulation of glucose transport in muscle from morbidly obese and diabetic subjects. J. Clin. Invest. 82:486-494.

9. Ciaraldi, T. P., O. G. Kolterman, and J. M. Olefsky. 1981. Mechanism of the postreceptor defect in insulin action in human obesity. Decrease in glucose transport system activity. J. Clin. Invest. 68:875-880.

10. Kashiwagi, A., M. A. Verso, J. Andrews, B. Vasquez, G. Reaven, and J. E. Foley. 1983. In vitro insulin resistance of human adipocytes isolated from subjects with noninsulin-dependent diabetes mellitus. J. Clin. Invest. 72:1246-1254.

11. Yang, Y. J., I. D. Hope, M. Ader, and R. N. Bergman. 1989. Insulin transport across capillaries is rate limiting for insulin action in dogs. J. Clin. Invest. 84:1620-1628.

12. Laasko, M., S. V. Edelman, G. Brechtel, and A. D. Baron. 1990 . Decreased effect of insulin to stimulate skeletal muscle blood flow in obese man. A novel mechanism for insulin resistance. J. Clin. Invest. 85:1844-1852.

13. Laasko, M., S. V. Edelman, G. Brechtel, and A. D. Baron. 1990. Impaired insulin-mediated skeletal muscle blood flow in patients with NIDDM. Diabetes. 41:1076-1083.

14. Laasko, M., S. V. Edelman, G. Brechtel, and A. D. Baron. 1992. Effects of epinephrine on insulin-mediated glucose uptake in whole body and leg muscle in humans: role of blood flow. Am. J. Physiol. 263:E199-204.

15. Anderson, E. A., R. P. Hoffman, T. W. Balon, C. A. Sinkey, and A. L. Mark. 1991. Hyperinsulinemia produces sympathetic neural activation and vasodilation in normal humans. J. Clin. Invest. 87:2246-2252.

16. Natali, A., G. Buzzigoli, S. Taddei, D. Santoro, M. Cerri, R. Pedrinelli, and E. Ferrannini. 1990. Effects of insulin on hemodynamics and metabolism in human forearm. Diabetes. 39:490-500.

17. Kolterman, O. G., L. J. Insel, M. Saekow, and J. M. Olefsky. 1980. Mechanisms of insulin resistance in human obesity. Evidence for receptor and postreceptor defects. J. Clin. Invest. 65:1272-1284.

18. Herbert, V., K. Law, C. Gottlieb, and S. Bleicher. 1965. Coated charcoal immunoassay of insulin. J. Clin. Endocrinol. Metab. 25:1375-1384.

19. Harvey, R. B., and A. J. Brothers. 1962. Renal extraction of p-aminohippurate and creatinine measured by continuous in vivo sampling of arterial and renal vein blood. Ann. NY Acad. Sci. 102:46-54.

20. Steele, R. 1959. Influence of glucose loading and injected insulin on hepatic glucose output. Ann. NY Acad. Sci. 82:420-430.

21. Finegood, D. T., R. N. Bergman, and M. Vranic. 1987. Estimation of endogenous glucose production during hyperinsulinemic-euglycemic glucose clamps: comparison of unlabelled and labelled exogenous glucose infusates. Diabetes. 36:914-924.

22. Gottesman, I., L. Mandarino, and J. Gerich. 1984. Use of glucose uptake and glucose clearance for the evaluation of insulin action in vivo. Diabetes. 33:184-191.

23. Motwani, J. G., and A. D. Struthers. 1992. Dose-response study of the redistribution of intravascular volume by angiotensin II in man. Clin. Sci. (Lond.). 82:397-405.

24. Li, T., and B. G. Zimmerman. 1990. In vivo comparison of renal and femoral vascular sensitivity and local angiotensin generation. Hypertension (Dallas). 15:204-209.

25. Leavens, N. R., A. E. Freedlender, M. J. Peach, and R. M. Carey. 1983. Control of renal function by intrarenal angiotensin II. Endocrinology. 112:43-49.
26. Laszlo, R., and G. Navar. 1983. Effects on renal hemodynamics of intra-arterial infusions of angiotensins I and II. Am. J. Physiol. 245:F181-F187.

27. Stockland, O., M. Molaug, J. Thorvaldson, and A. Ilebekk. 1986. Angiotensin II infusion during $\beta$-adrenergic stimulation by isoproterenol: effects on hepatic, splenic and cardiac blood volumes and on the magnitude and distribution of cardiac output in the dog. Acta Physiol. Scand. 127:387-394.

28. DeBono, E., G. D. J. Lee, F. R. Mottram, G. W. Pickering, J. J. Brown, H. Keen, W. S. Peart, and P. H. Sanderson. 1963. The action of angiotensin in man. Clin. Sci. (Lond.). 25:123-157.

29. Gasic, S., G. Heinz, C. Kleinbloesem, and A. Korn. 1989. Effects of ACE inhibition with cilazapril on splanchnic and systemic haemodynamics in man. Br. J. Clin. Pharmacol. 27(Suppl 2):S225-S234.

30. Gasic, S., G. Heinz, and C. Kleinbloesem. 1990. Quantitative evidence of peripheral conversion of angiotensin within the human leg: effects of local angiotensin-I administration and angiotensin-converting enzyme inhibition on regional blood flow and angiotensin-II balance across the leg. Naunyn-Schmiedeberg's Arch. Pharmacol. 342:436-440.

31. Gans, R. O. B., H. J. G. Bilo, W. W. A. van Maarschalkerweerd, R. H. Heine, J. J. P. Nauta, and A. J. M. Donker. 1991. Exogenous insulin augments in healthy volunteers the cardiovascular reactive to noradrenaline but not to angiotensin II. J. Clin. Invest. 88:512-518.

32. Liang, C.-S., J. U. Doherty, R. Faillace, K. Maekawa, S. Arnold, H. Gavras, and W. B. Hood. 1982. Insulin infusion in conscious dogs. Effects on systemic and coronary hemodynamics, regional blood flow and plasma catecholamines. J. Clin. Invest. 62:1321-1336.

33. O'Hare, J. A., K. L. Minaker, G. S. Meneilly, J. W. Rowe, J. A. Pallotta, and J. B. Young. 1989. Effect of insulin on plasma norepinephrine and 3,4-dihydroxyphenylalanine in obese men. Metab. Clin. Exp. 38:322-329.

34. Rowe, J. W., J. B. Young, K. L. Minaker, A. L. Stevens, J. Pallotta, and L. Lansberg. 1981. Effect of insulin and glucose infusions on sympathetic nervous system activity in normal man. Diabetes. 30:219-225.

35. Anderson, E. A., T. W. Balon, R. P. Hoffman, C. A. Sinkey, and A. L. Mark. 1992. Insulin increases sympathetic activity but not blood pressure in borderline hypertensive patients. Hypertension (Dallas). 19:621-627.

36. Lembo, G., R. Napoli, B. Capaldo, V. Rendina, G. Iaccarino, M. Volpe, B. Trimarco, and L. Sacca. 1990. Abnormal sympathetic overactivity evoked by insulin in the skeletal muscle of patients with essential hypertension. J. Clin. Invest. 90:24-29.

37. DeFronzo, R. A., M. Goldberg, and Z. Agus. 1976. The effects of glucose and insulin on renal electrolyte transport. J. Clin. Invest. 58:83-90.

38. Norgaard, K., T. Jensen, P. Skott, B. Thorsteinsson, N. E. Bruun, J. Giese, and B. Feldt-Rasmussen. 1991. Effects of insulin on renal haemodynamics and sodium handling in normal subjects. Scand. J. Clin. Lab. Invest. 51:367-376.

39. Zierler, B. K., T. R. Kirkman, L. W. Kraiss, W. G. Reiss, J. R. Horn, L. A. Bauer, A. W. Clowes, and T. R. Kohler. 1992. Accuracy of duplex scanning for measurement of arterial volume flow. J. Vasc. Surg. 16:520-526.

40. Buchanan, T. A., G. F. Sipos, S. Gadalah, Y.-P. Yip, D. J. Marsh, W. Hsueh, and R. N. Bergman. 1991. Glucose tolerance and insulin action in rats with renovascular hypertension. Hypertension (Dallas). 18:341-347.

41. Kotchen, T. A., H. Y. Ahang, M. Covelli, and N. Blehsdhmidt. 1991. Insulin resistance and blood pressure in Dahl rats and in one-kidney, one-clip hypertensive rats. Am. J. Physiol. 261:E692-E697.

42. Marigliano, A., R. Tedde, L. A. Sechi, A. Pala, G. Pisanu, and A. Pacifico. 1990. Insulinemia and blood pressure: relationships in patients with primary and secondary hypertension, with and without glucose metabolism impairment. Am. J. Hypertens. 3:521-526.

43. Buchanan, T. A. 1991. Insulin resistance and hyperinsulinemia: implications for the pathogenesis and treatment of hypertension. Semin. Nephrol. 11:512-522. 